JEL Classification: M120

DOI: $10.46361 / 2449-2604.7 .3 .2020 .17-25$

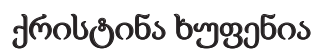

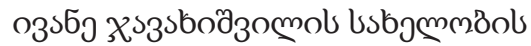

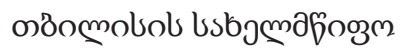

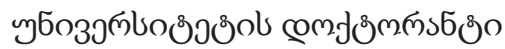

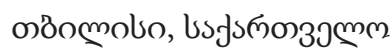

E-mail: kristina.khupenia272@eab.tsu.edu.ge orcid.org/ 0000-0001-6789-0376

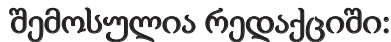

Бмдав эюо, 2020

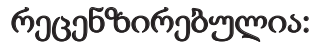

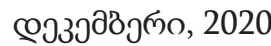

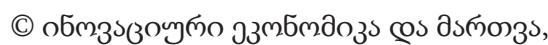
2020

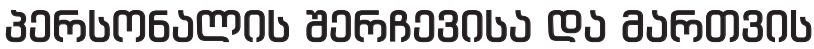

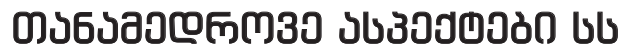

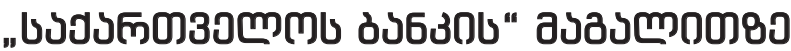

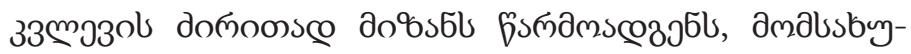

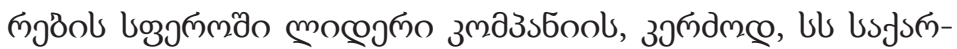

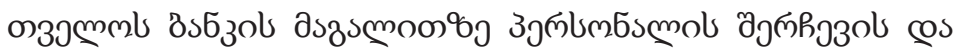

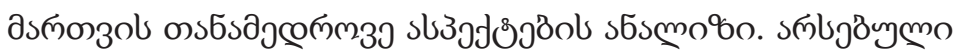

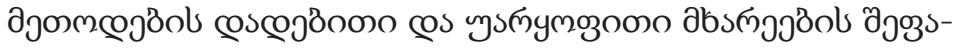

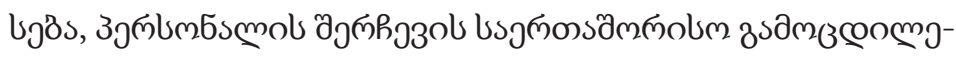

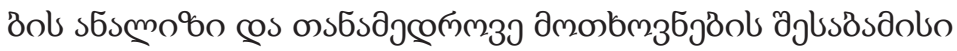

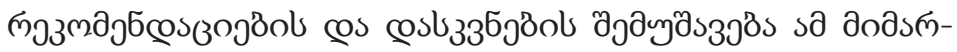

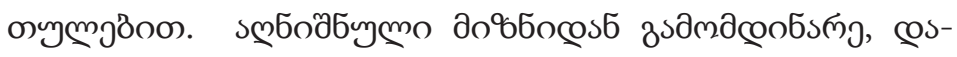

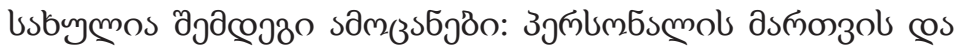

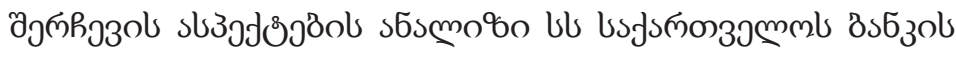

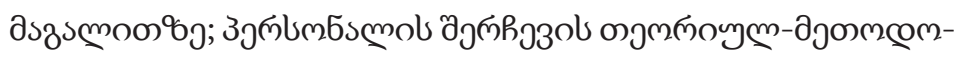

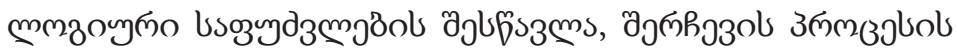

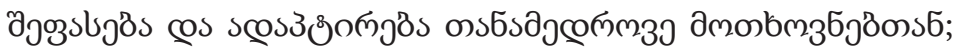

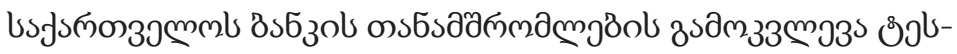

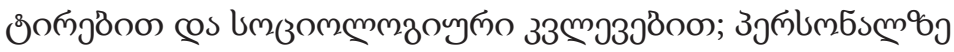

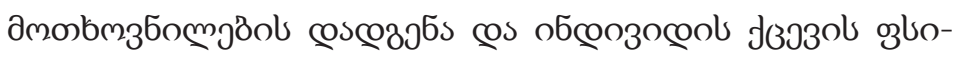

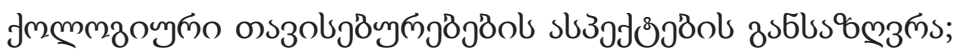

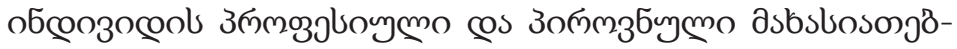

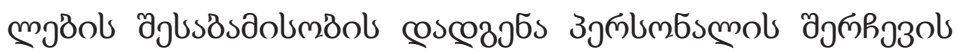

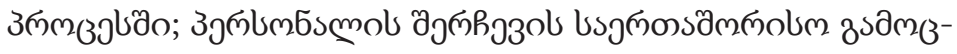
conggöols s6smo\%o.

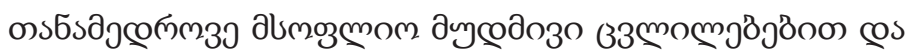

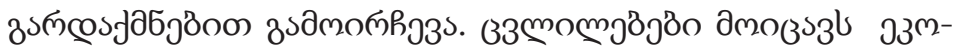

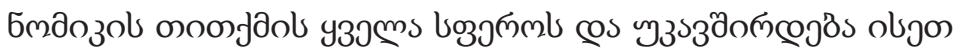

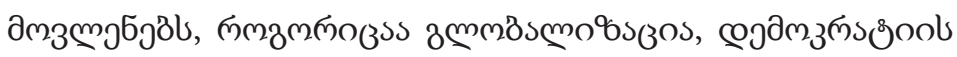

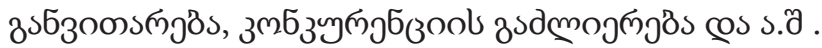

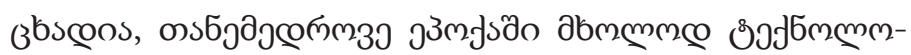

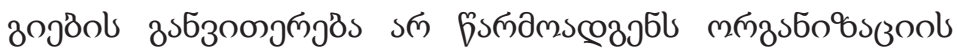

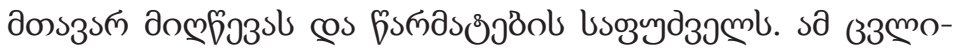

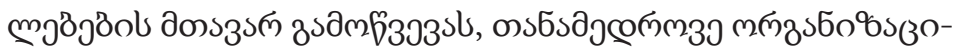

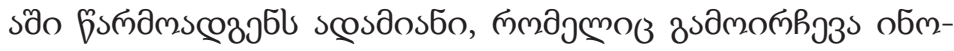

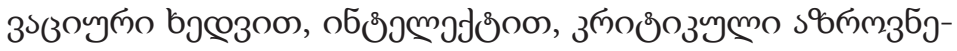

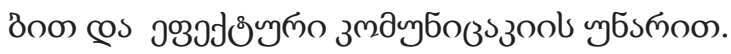

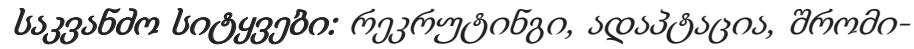

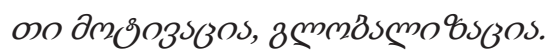


JEL Classification: M120

DOI: 10.46361/2449-2604.7.3.2020.17-25

\section{KRISTINA KHUPENIA}

PHD student of

Ivane Javakhishvili State University

Tbilisi, Georgia

E-mail: kristina.khupenia272@eab.tsu.edu.ge orcid.org/ 0000-0001-6789-0376

Edited by:

November, 2020

Reviewed by:

December, 2020

\section{ANALYSIS OF PERSONNEL MANAGEMENT AND SELECTION ASPECTS ON THE EXAMPLE OF JSC BANK OF GEORGIA}

The main purpose of the research is to analyze the modern aspects of personnel selection and management on the example of a leading company in the field of services, in particular, JSC Bank of Georgia. Evaluate the pros and cons of existing methods, analyze the international experience in staff selection and develop the recommendations and conclusions relevant to modern requirements in this area. Based on this goal, the following tasks are set: Analysing of personnel management and selection aspects on the example of JSC Bank of Georgia; Studying of the theoretical-methodological bases of personnel selection, evaluating of the selection process and adapting to modern requirements; Surveying of Bank of Georgia employees through testing and sociological research; Determining staffing needs and aspects of the psychological characteristics of an individual's behavior; Determining the relevance of an individual's professional and personal characteristics in the personnel selection process. Analyzing of international experience in personnel selection.

The modern world is characterized by constant changes and transformations. The changes cover almost all areas of the economy and are related to events such as globalization, the development of democracy, the strengthening of competition, etc.

Clearly, in the modern era the development of technology is not the only main achievement and foundation of success of an organization. The main challenge of these changes in a modern organization is a person who is distinguished by innovative vision, intellect, critical thinking and effective communication skills.

Key words: Recruitment, Adaptation, Labor Motivation, Globalization

(C) Innovative Economics and Management, 2020 


\section{चjuszsemo}

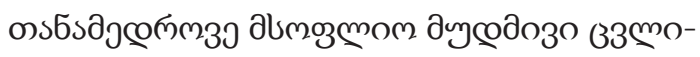

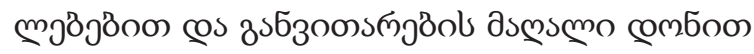

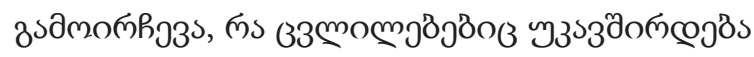

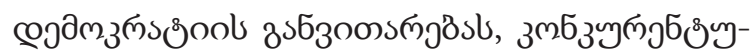

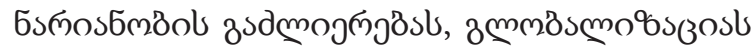

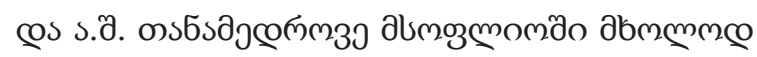

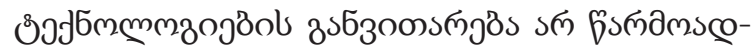

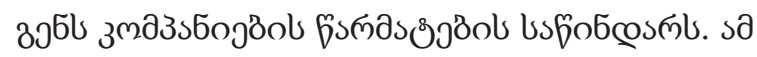

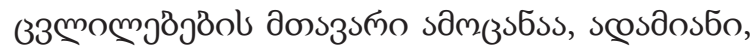

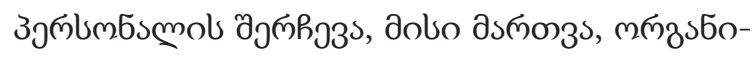

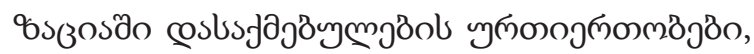

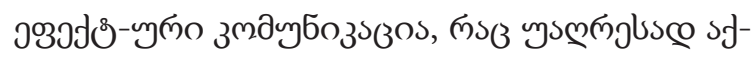

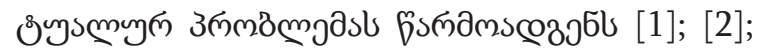
[4].

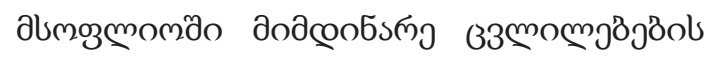

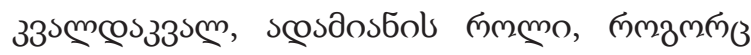

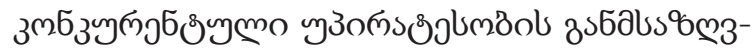

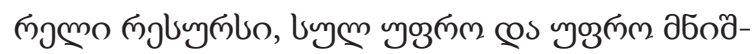

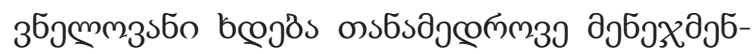

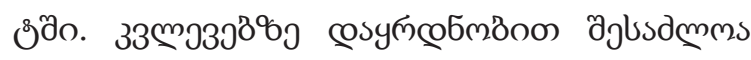

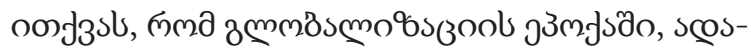

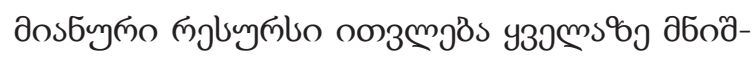

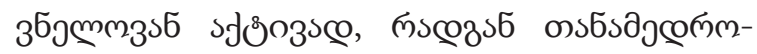

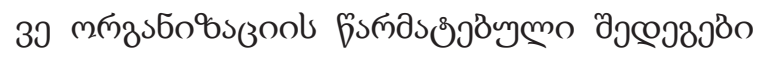

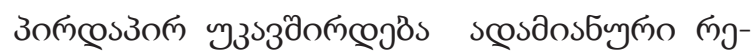

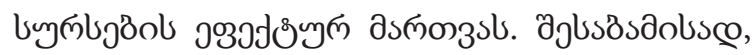

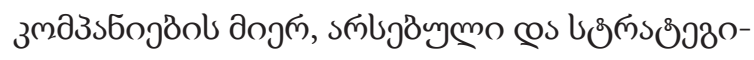

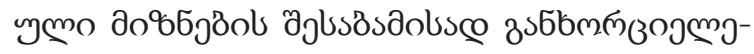

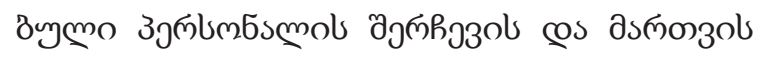

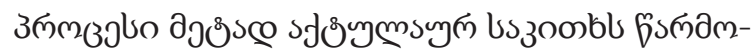

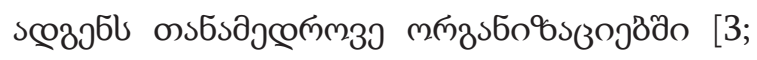
$5]$.

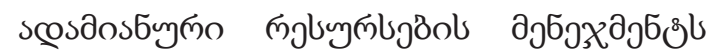

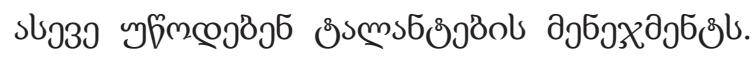

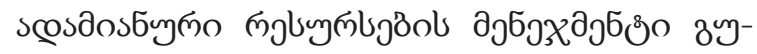

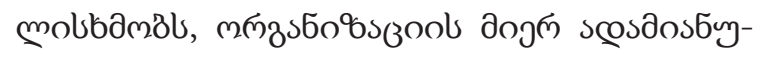

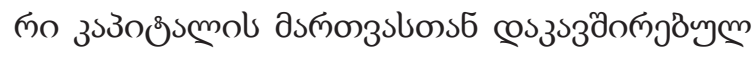
бjöolanogn uszoobl.

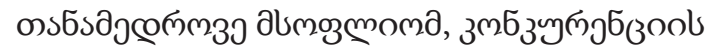

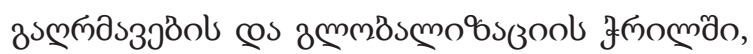

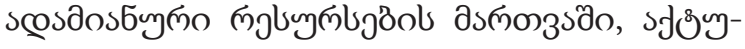

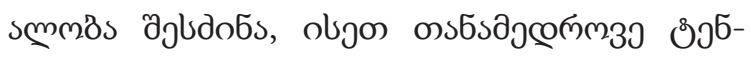

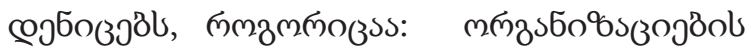

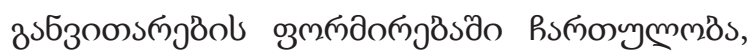

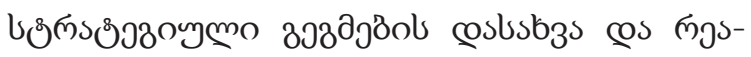

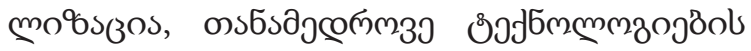

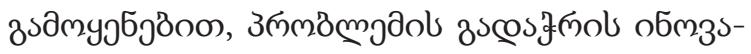

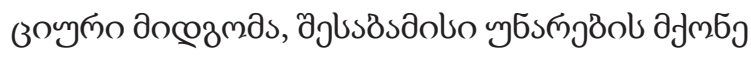

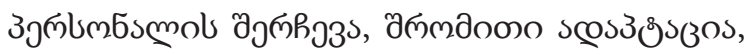

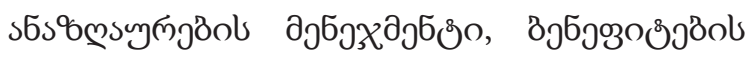

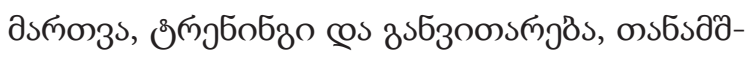

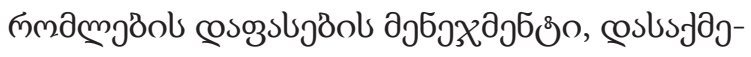

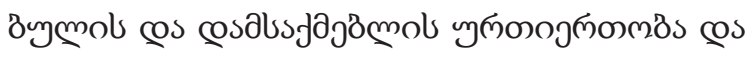

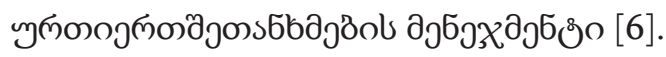

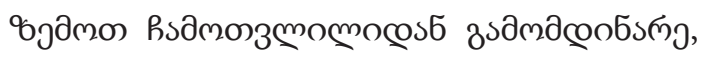

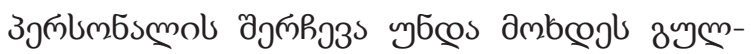

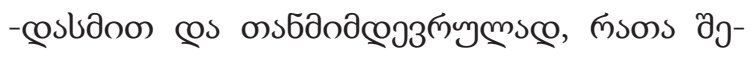

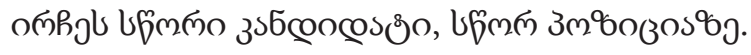

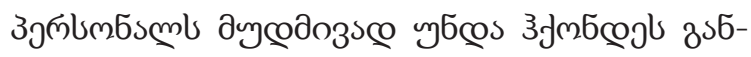

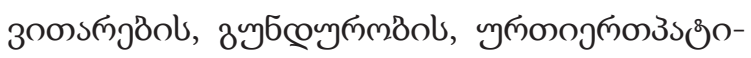

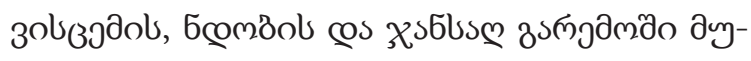
asmöol bsayssmgßs.

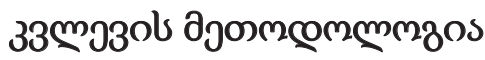

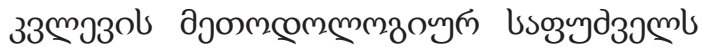

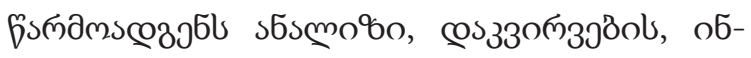

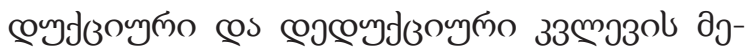

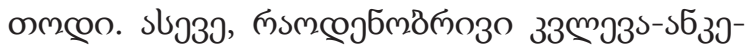

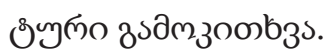

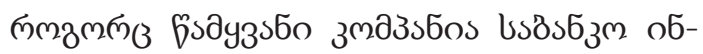

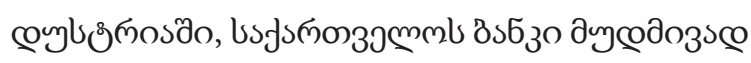

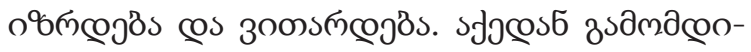

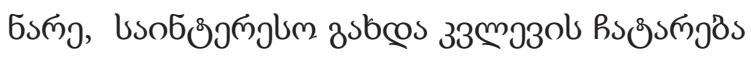

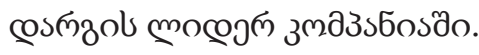

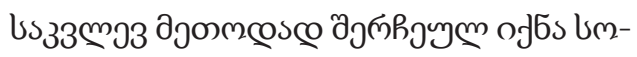

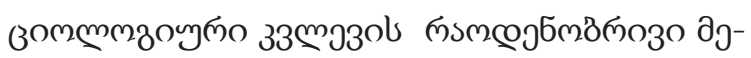

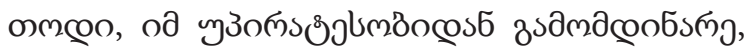

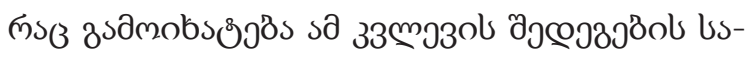

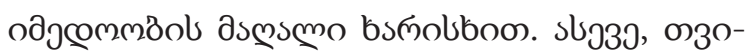

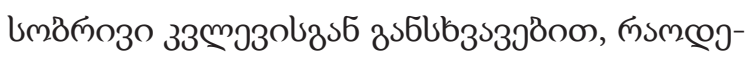

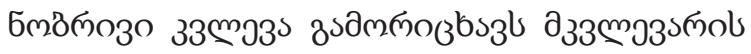

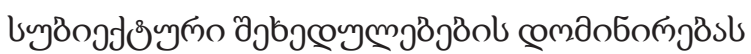




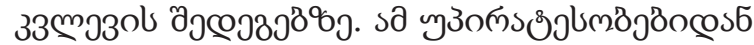

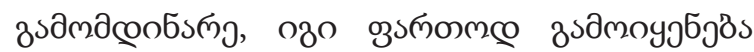

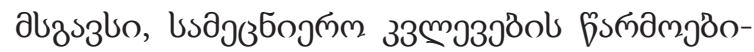
bist.

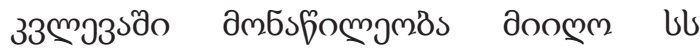

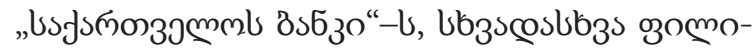

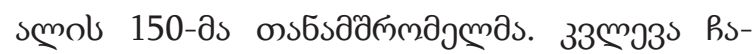

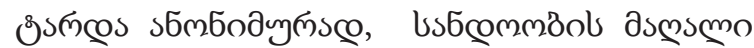

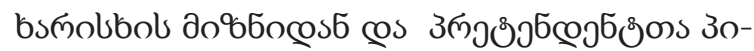

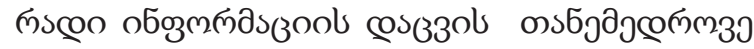

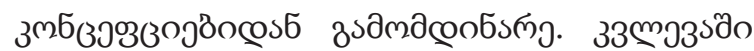

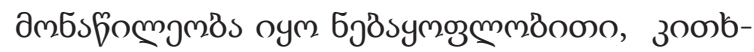

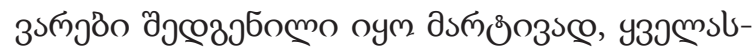

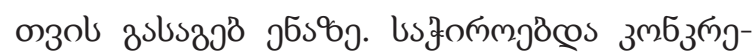

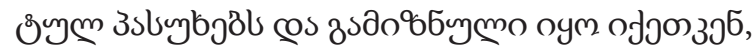

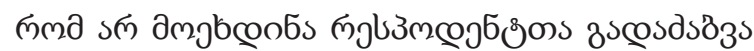

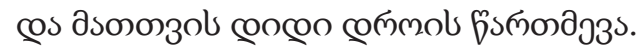

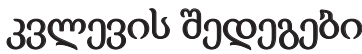

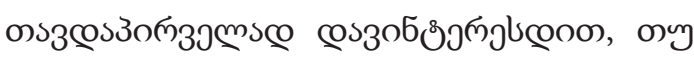

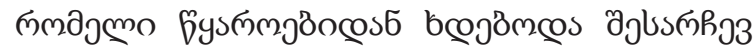

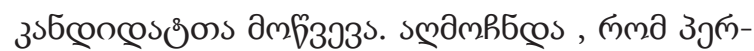

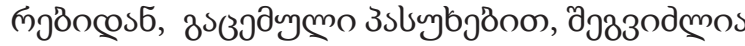

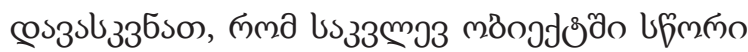

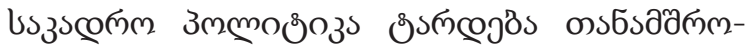
agmons aj

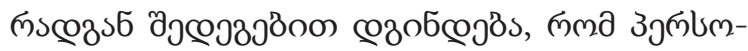
bsmol дmºç

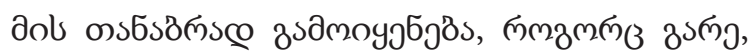

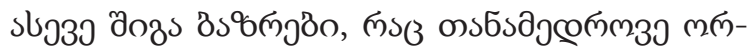

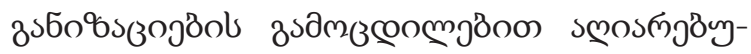

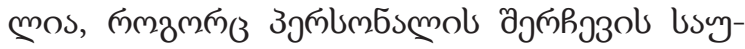

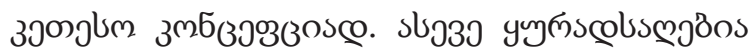

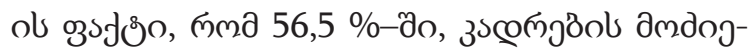

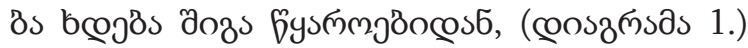

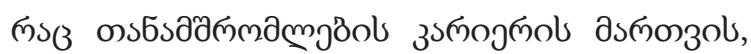

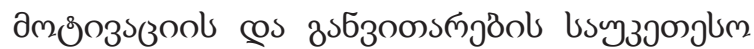

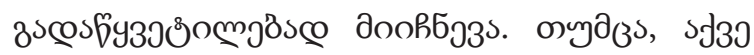

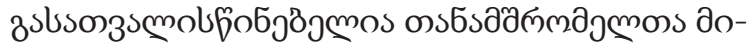

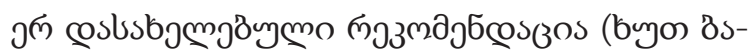

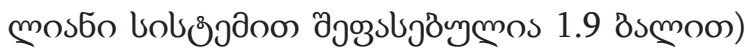

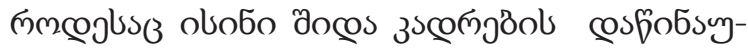

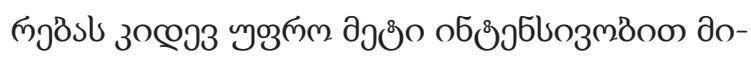

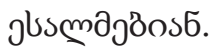

cooszmsas 1.

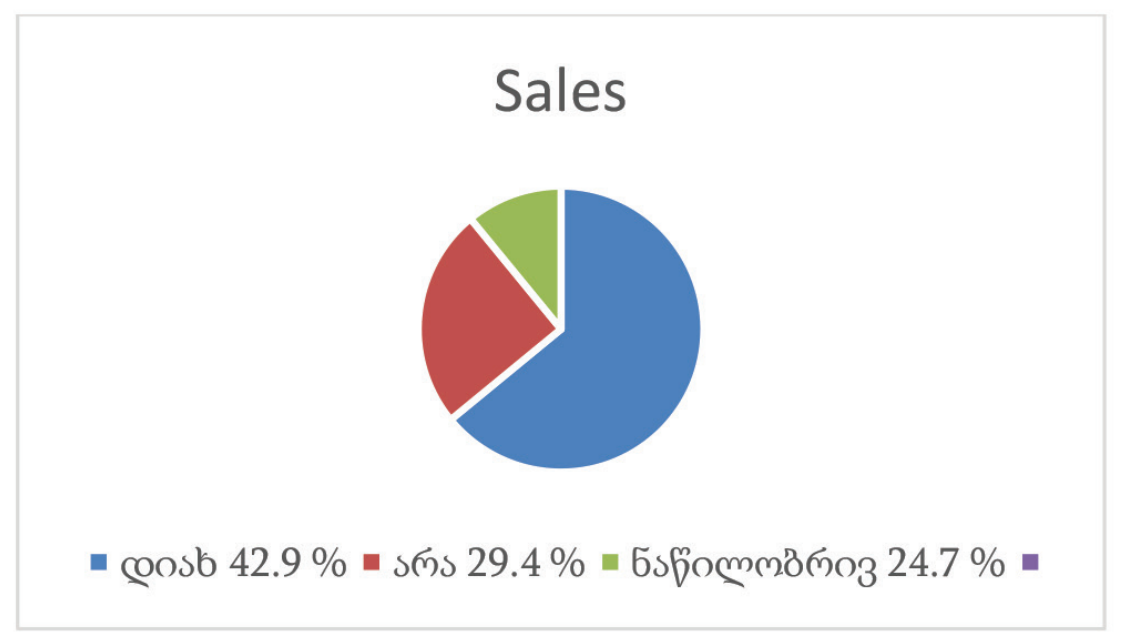

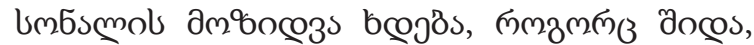

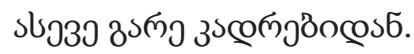

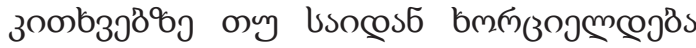

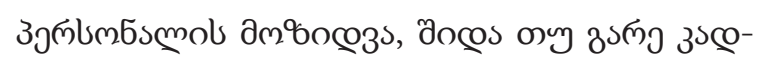

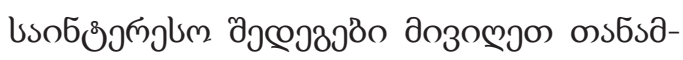

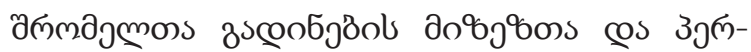

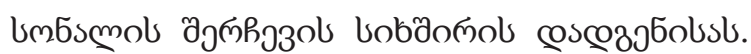

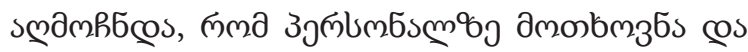

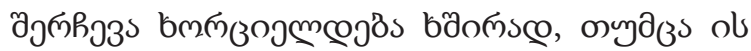


coszmsas 2.

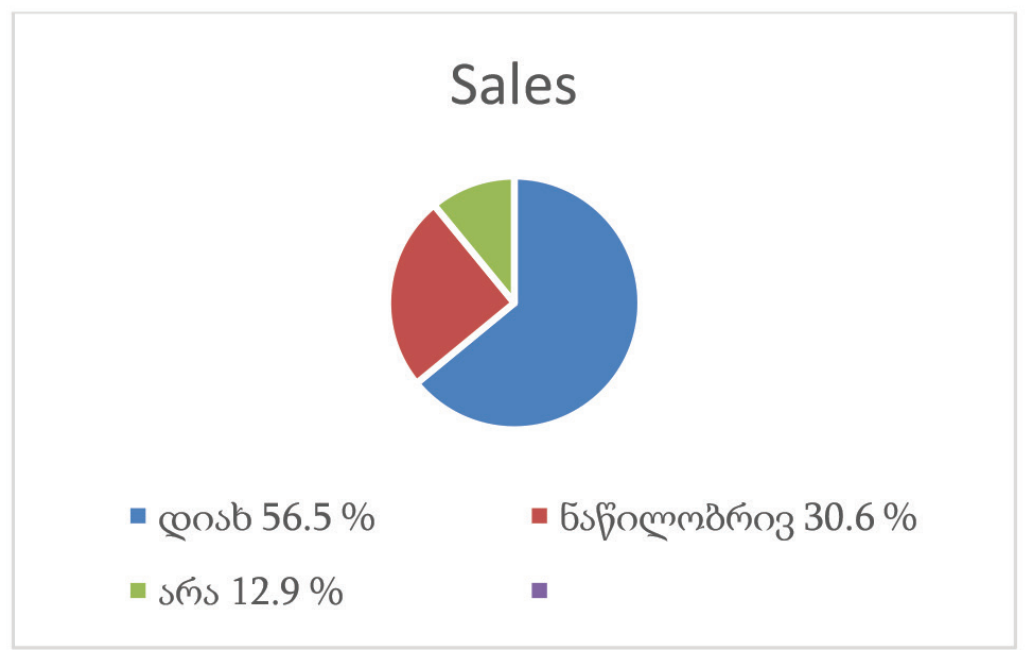

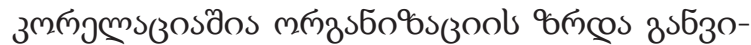

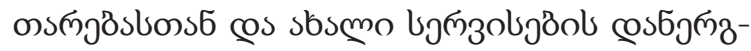

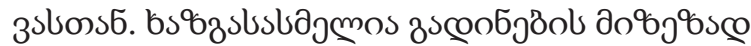
৮ঞ্গু

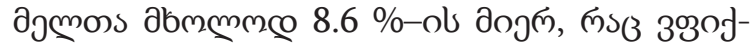

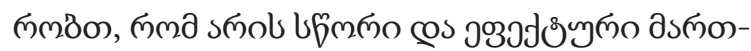

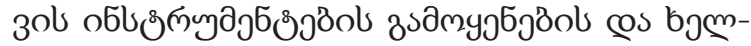

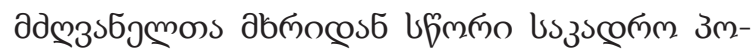

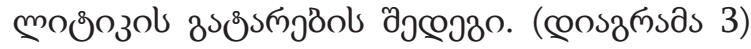

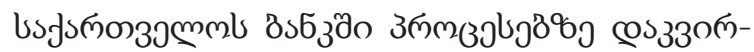

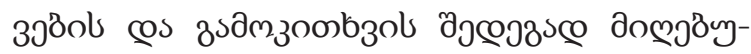

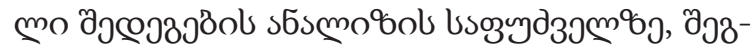

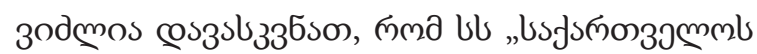

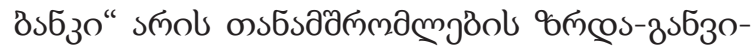

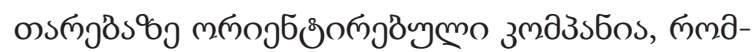

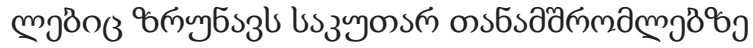

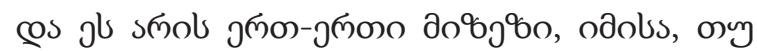

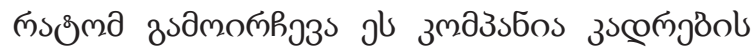

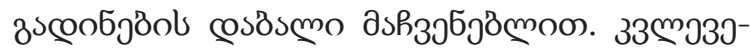

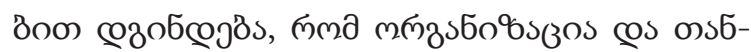

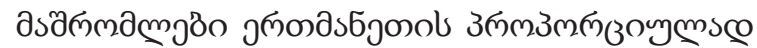

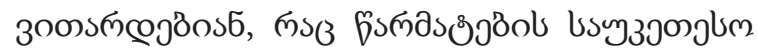

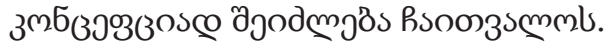

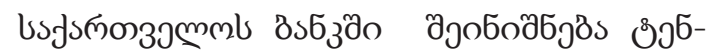

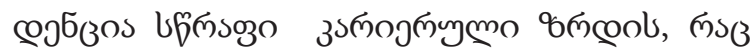

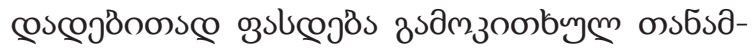

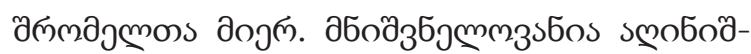

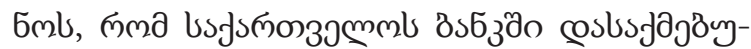

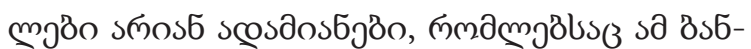

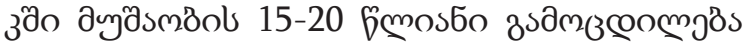

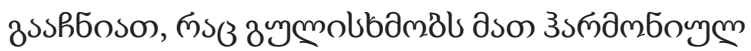

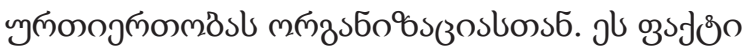

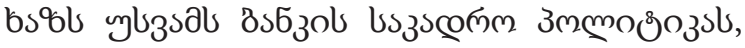

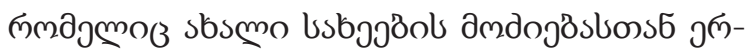

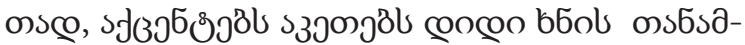

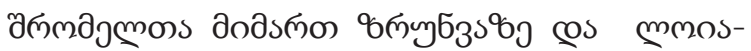

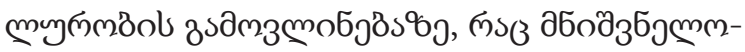

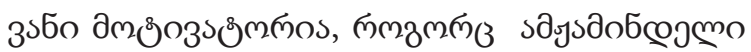

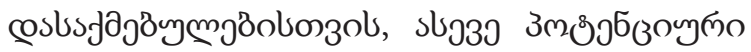

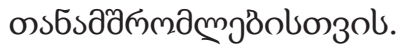

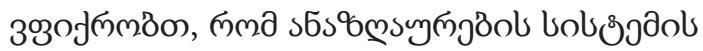



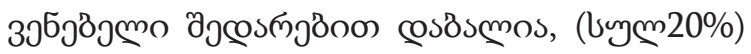

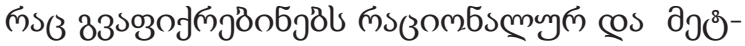

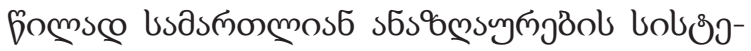
วs\%ว.

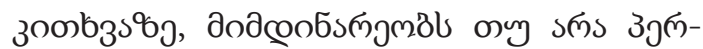

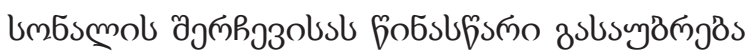

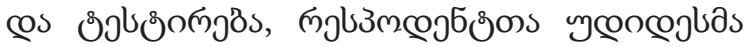

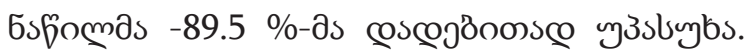

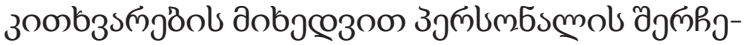

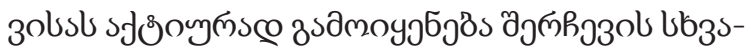

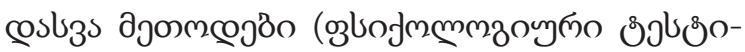

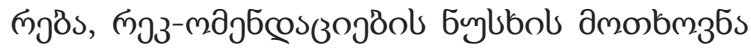

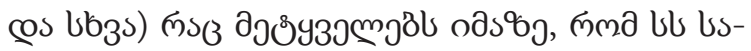

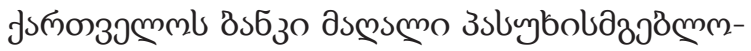


cooszmsas 3.

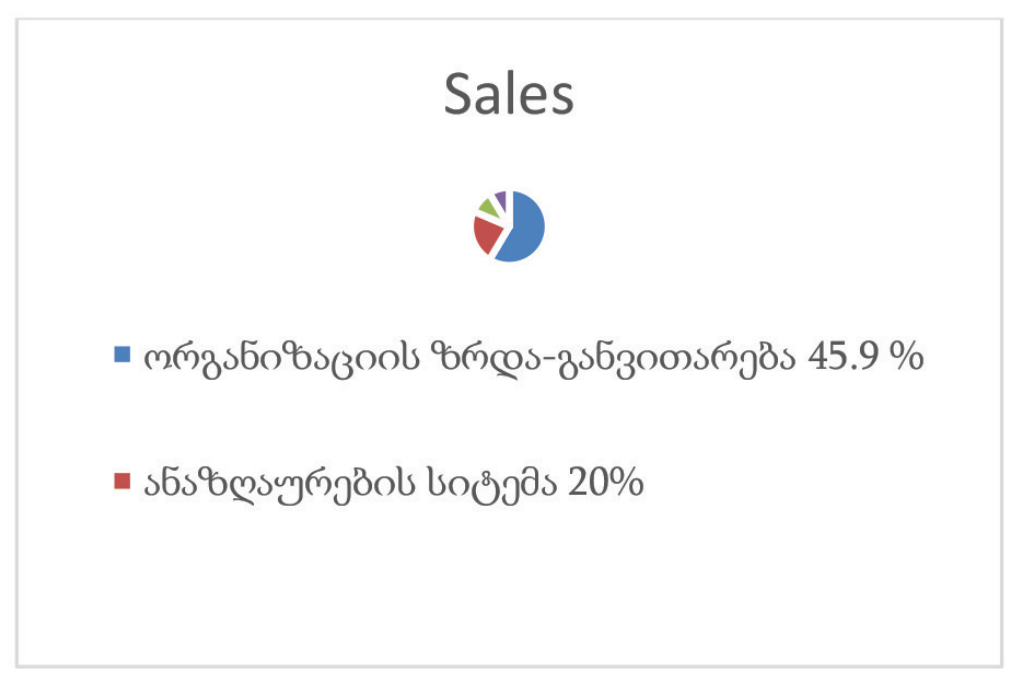

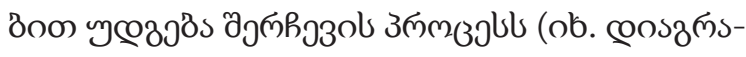

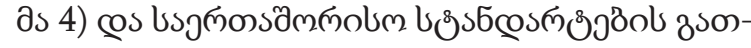

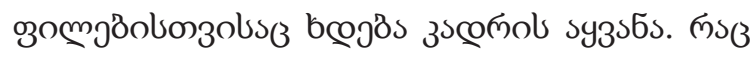

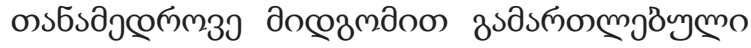

coszinsas 4.

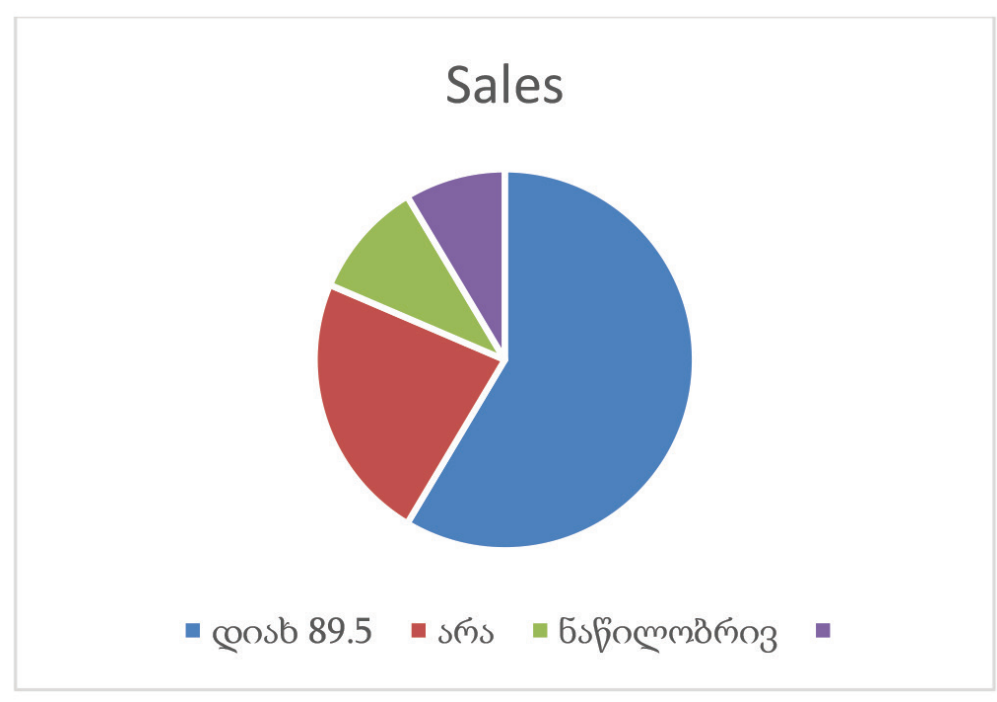

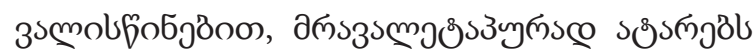

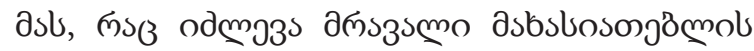

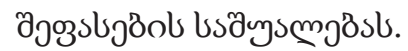

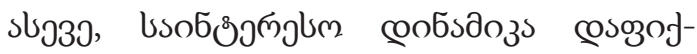

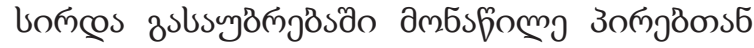

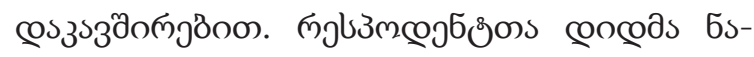

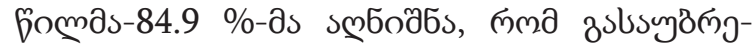

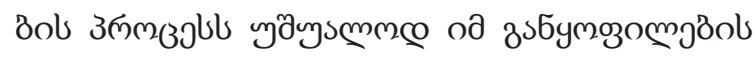

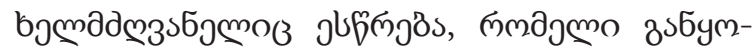

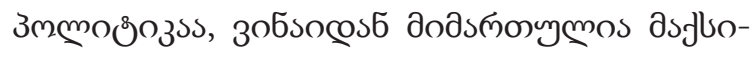

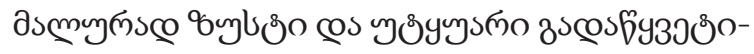

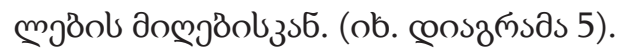

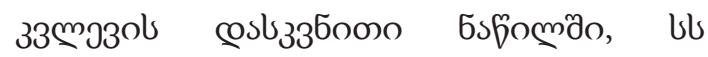

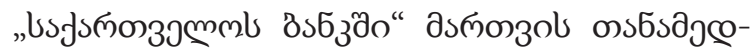

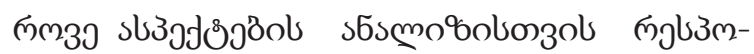

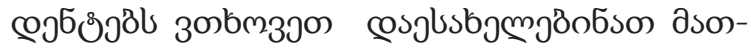

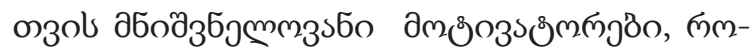

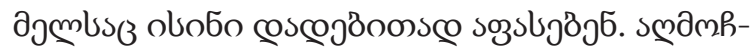


cooszmsas 5.

\section{Sales}

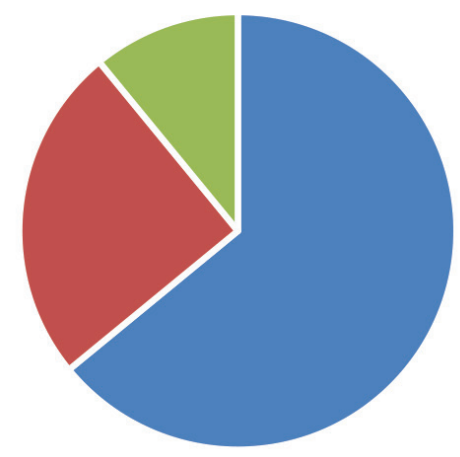

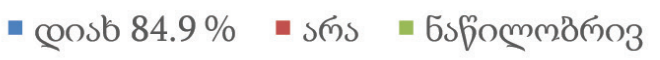

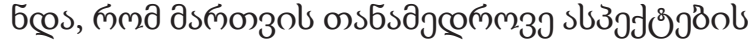

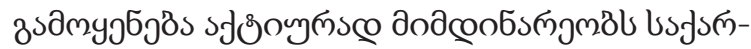

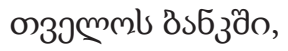

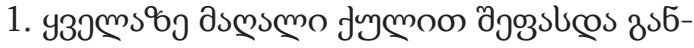

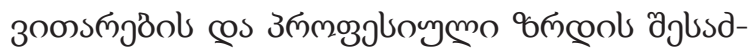

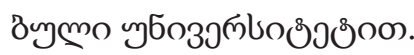

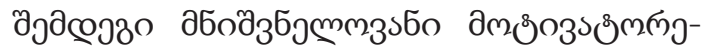

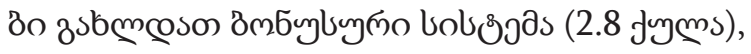

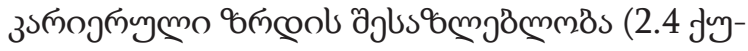

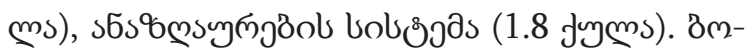

ূoszmsas 6.

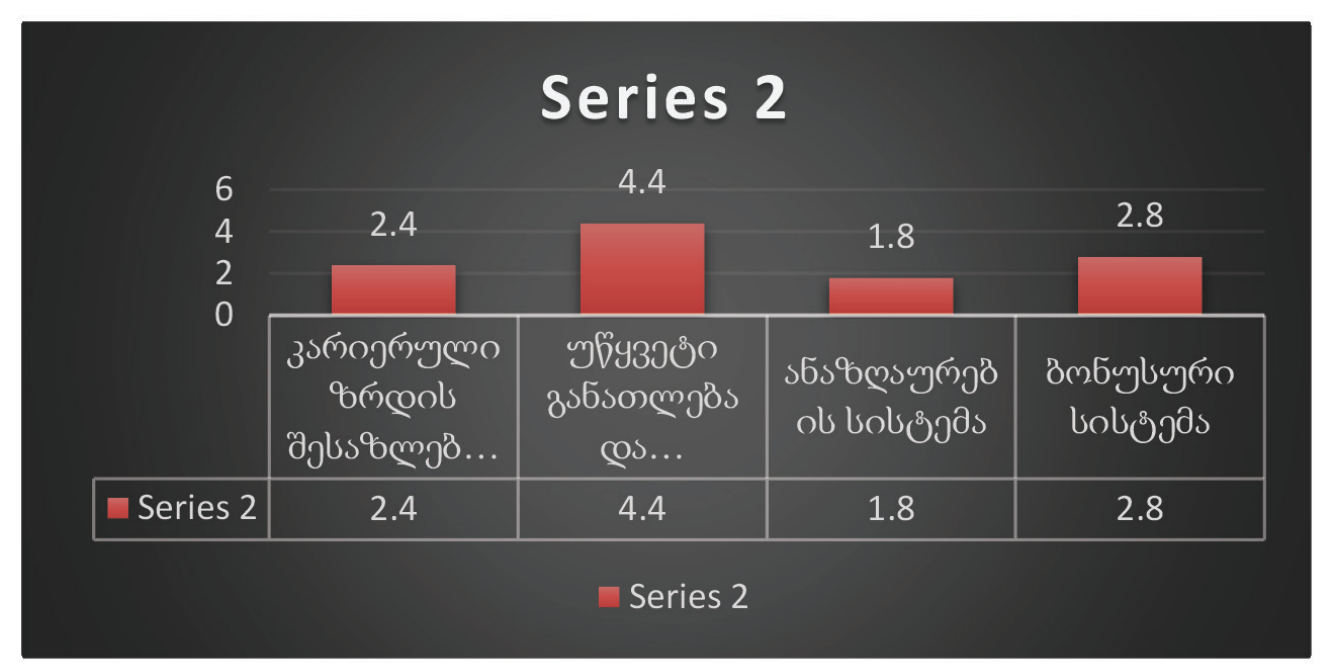

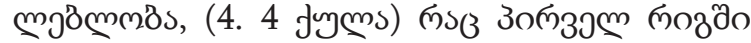

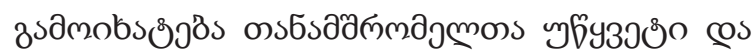

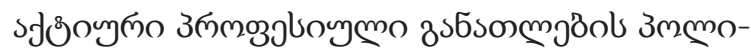

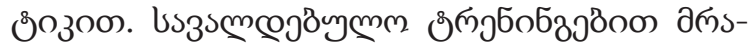
उ

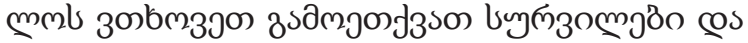

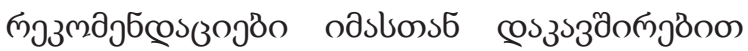

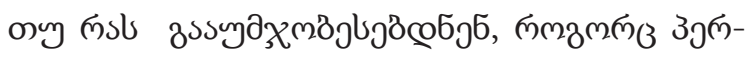

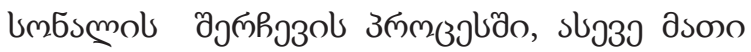
asmonzol zumobon. 
cooszmsas 7.

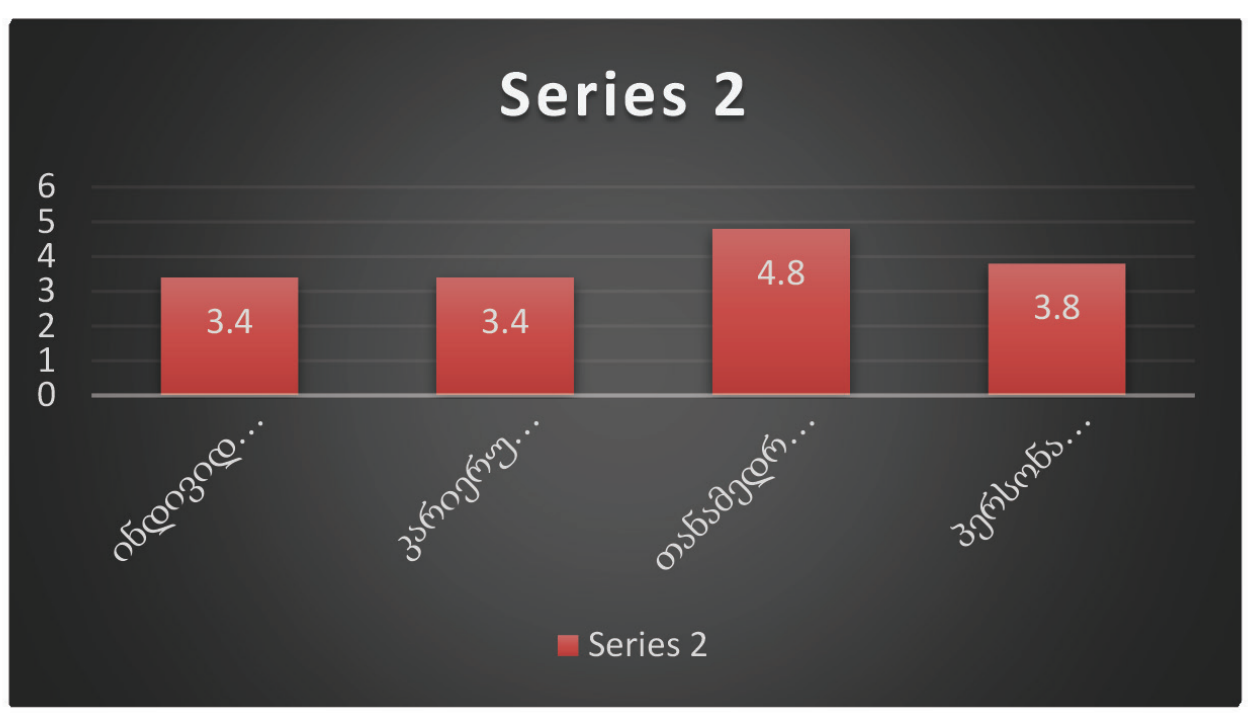

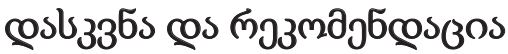

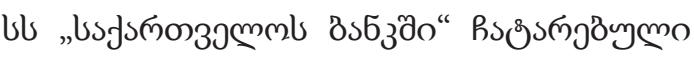

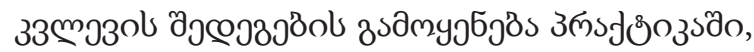

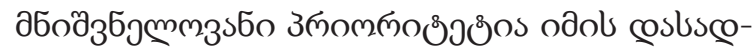

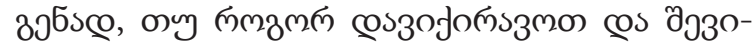

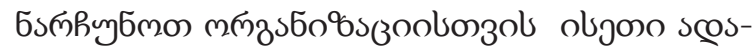

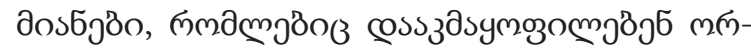

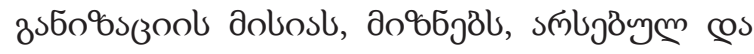
дмдзззм дмовьмзбјљl.

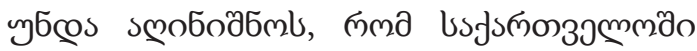

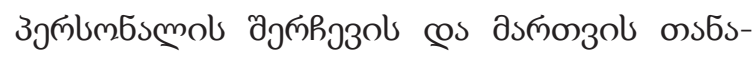



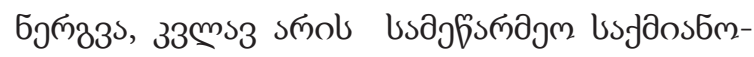

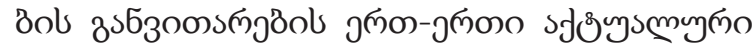
зпмдмладs.

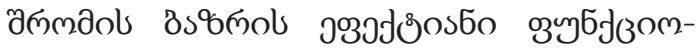

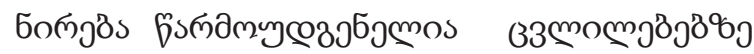

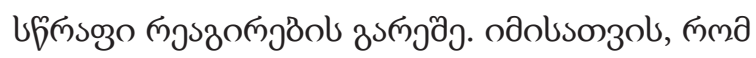

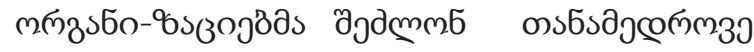

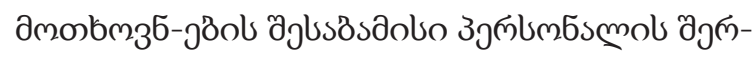

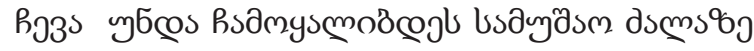

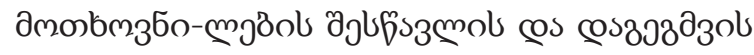

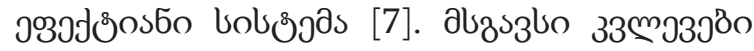

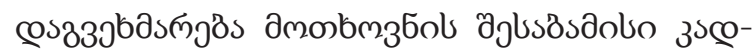

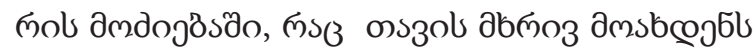

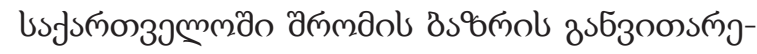

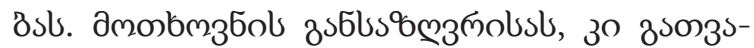

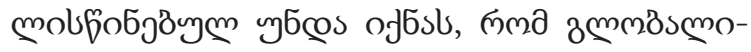

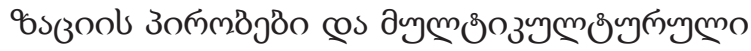

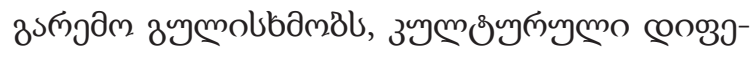

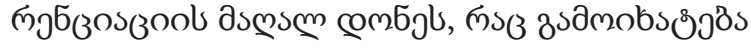

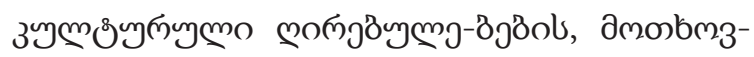

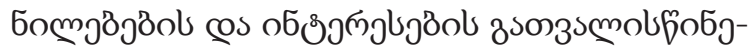

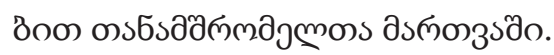

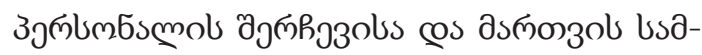

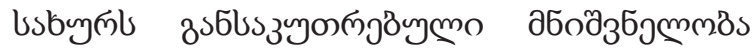

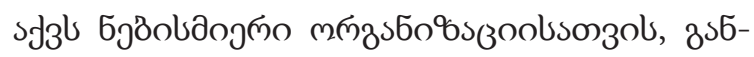

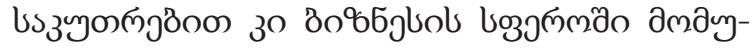

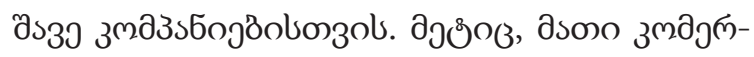

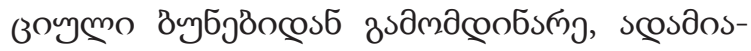

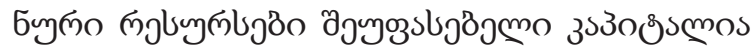

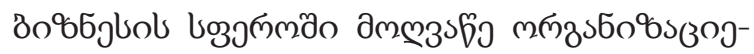

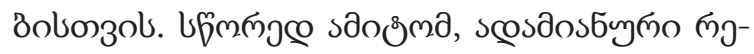

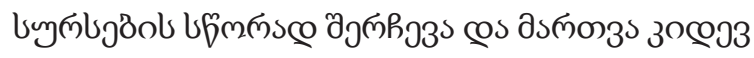

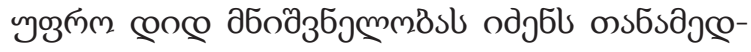

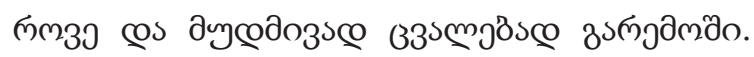

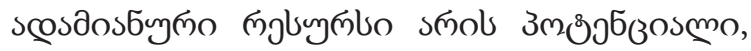

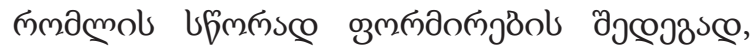

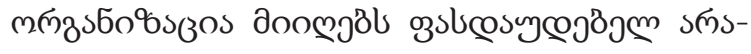

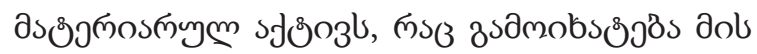

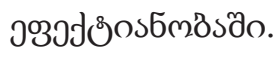

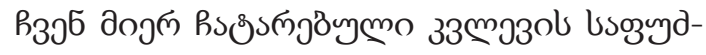

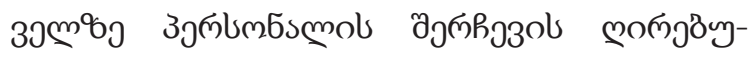




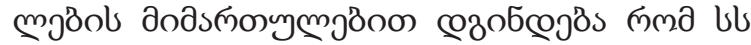

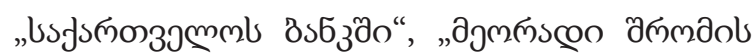

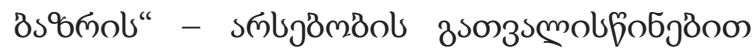

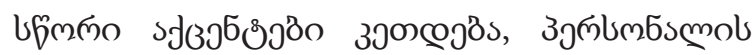

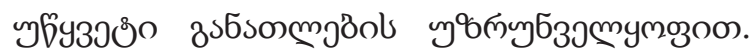

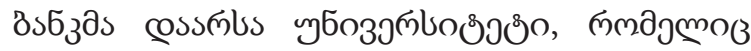

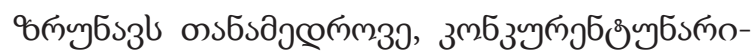

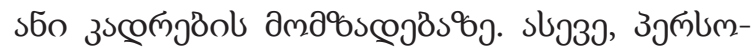

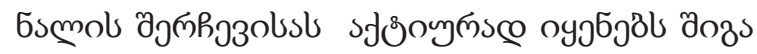

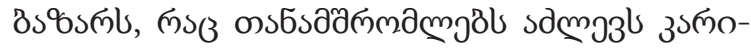

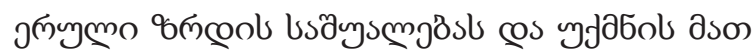

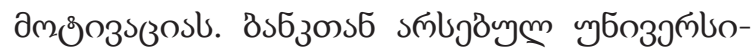

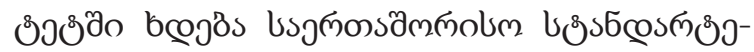

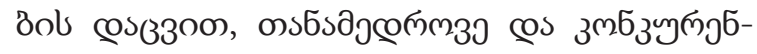

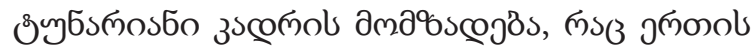

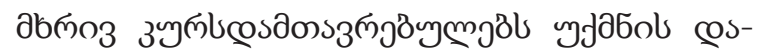

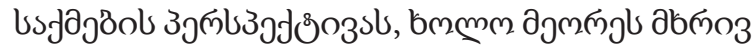

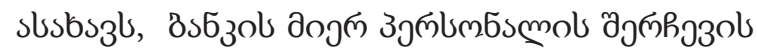

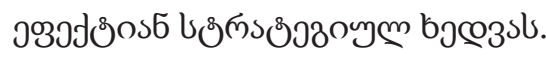

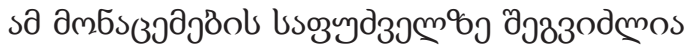

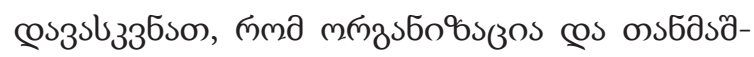

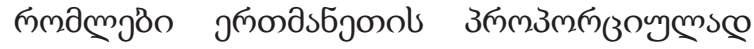

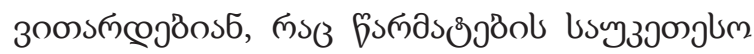

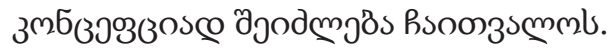

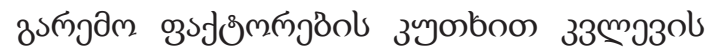

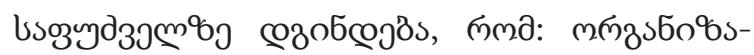

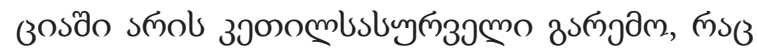

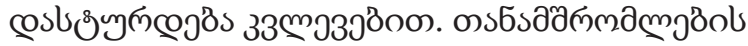

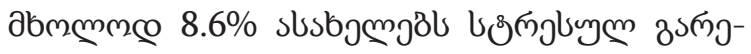

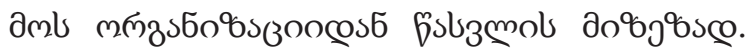

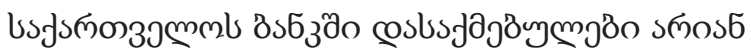

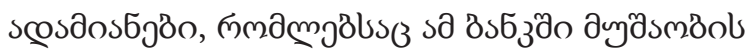

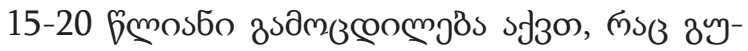

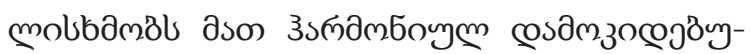

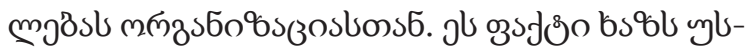

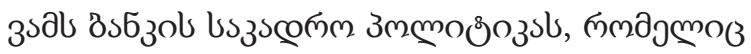

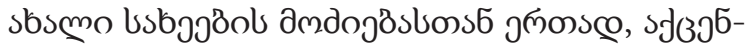

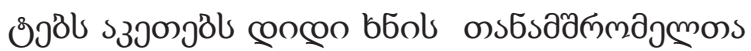

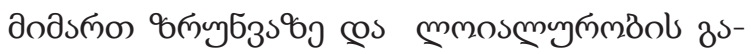

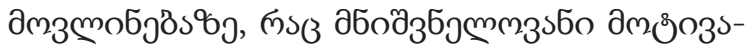

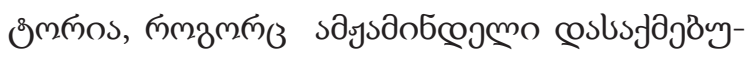

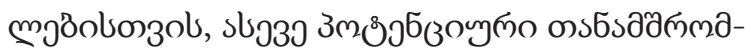
mjöolsonsol.

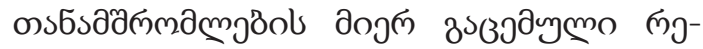

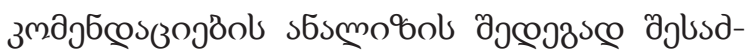

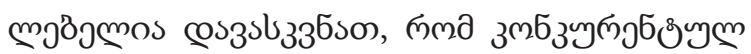

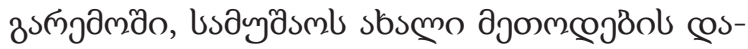

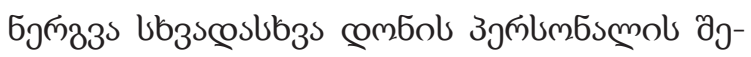

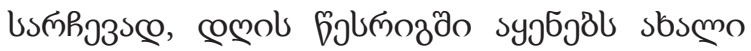

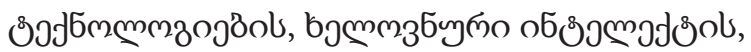

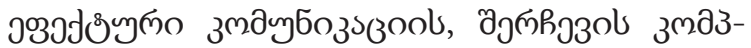

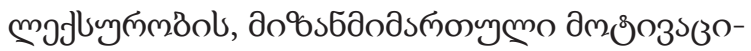

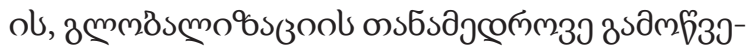

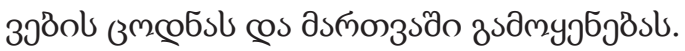

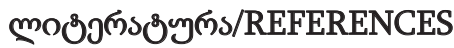

[1] И. И. Исаченко и др. „Управление человеческими ресурсами“. МГУ печати. Учебное пособие для студентов.

[2] Армстронг М. Практика управления человеческими ресурсами. 10-е издание.

[3] Мескон М., Альберт М., Хедоури Ф.- Основы менеджмента-Перевод с английского.

[4] Общая редаксия Л.И.Евенко.-Москва: Издательство «Дело»,

[5] Курс Управлениа Экономикой, Б. А. Райзберг М. (Питер), 2003;

[6] Кафидров, управление человеческими ресурсамию 2012

[7] “Human Resource Management”, Garry Dessler. 2005 